from UK public sources and encompassed annual drug costs ( $£ 268 \mathrm{FF} / \mathrm{VI} ; £ 491$ usual care), and COPD exacerbation management costs (moderate $£ 114$; severe $£ 2,053$ ).

Results Substituting usual care with FF/VI is likely to be associated with reduced COPD medication and exacerbation management costs. Total annual savings of $£ 34,000$ were obtained for a population of 1000 patients with COPD.

Conclusion In an everyday UK clinical setting, substituting usual care with FF/VI in patients with COPD can result in substantial annual cost savings. These results are relevant for clinicians and health care organisations.
P58

EFFICACY OF BUDESONIDE/FORMOTEROL IN COPD PATIENTS WITH A POST-BRONCHODILATOR FEV1 50 TO $<70 \%$ OF PREDICTED NORMAL: POOLED ANALYSIS ACROSS FOUR PHASE III/IV STUDIES

${ }^{1} \mathrm{C}$ Jorup, ${ }^{2} \mathrm{GD}$ James, ${ }^{3} \mathrm{~K}$ Pemberton, ${ }^{1} \mathrm{G}$ Eckerwall. ${ }^{1}$ AstraZeneca RandD, Gothenburg, Sweden: ${ }^{2}$ PHASTAR Ltd, London, UK: ${ }^{3}$ AstraZeneca, Macclesfield, UK

\subsection{6/thoraxjnl-2016-209333.201}

Background GOLD guidelines have changed from classifying COPD severity using pre-bronchodilator $\mathrm{FEV}_{1}$ to classifying severity based on post-bronchodilator $\mathrm{FEV}_{1}$. We therefore conducted a pooled post-hoc analysis of four budesonide/formoterol (Symbicort ${ }^{\circledast}$ ) Turbuhaler ${ }^{\circledast}$ trials in COPD (which included patients based on pre-bronchodilator $\mathrm{FEV}_{1}$ ), assessing efficacy and safety

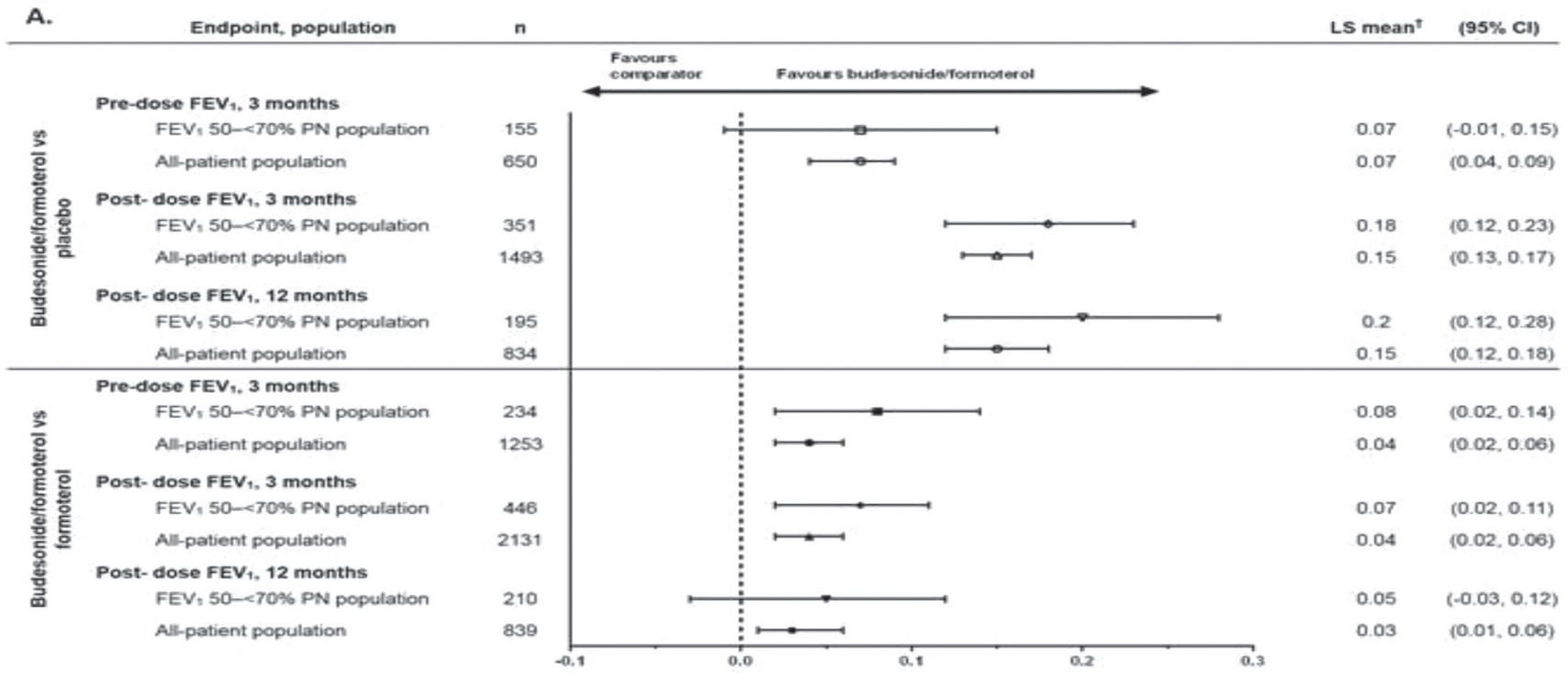

LS mean of the difference in change of FEV, from baseline

The LS mean is the difference between budesonide/formoterol and the comparison treatment in mean change from baseline FEV, determined by ANCOVA

B.

Endpoint, population

n

Rate ratio ${ }^{2}$

(95\% C1)

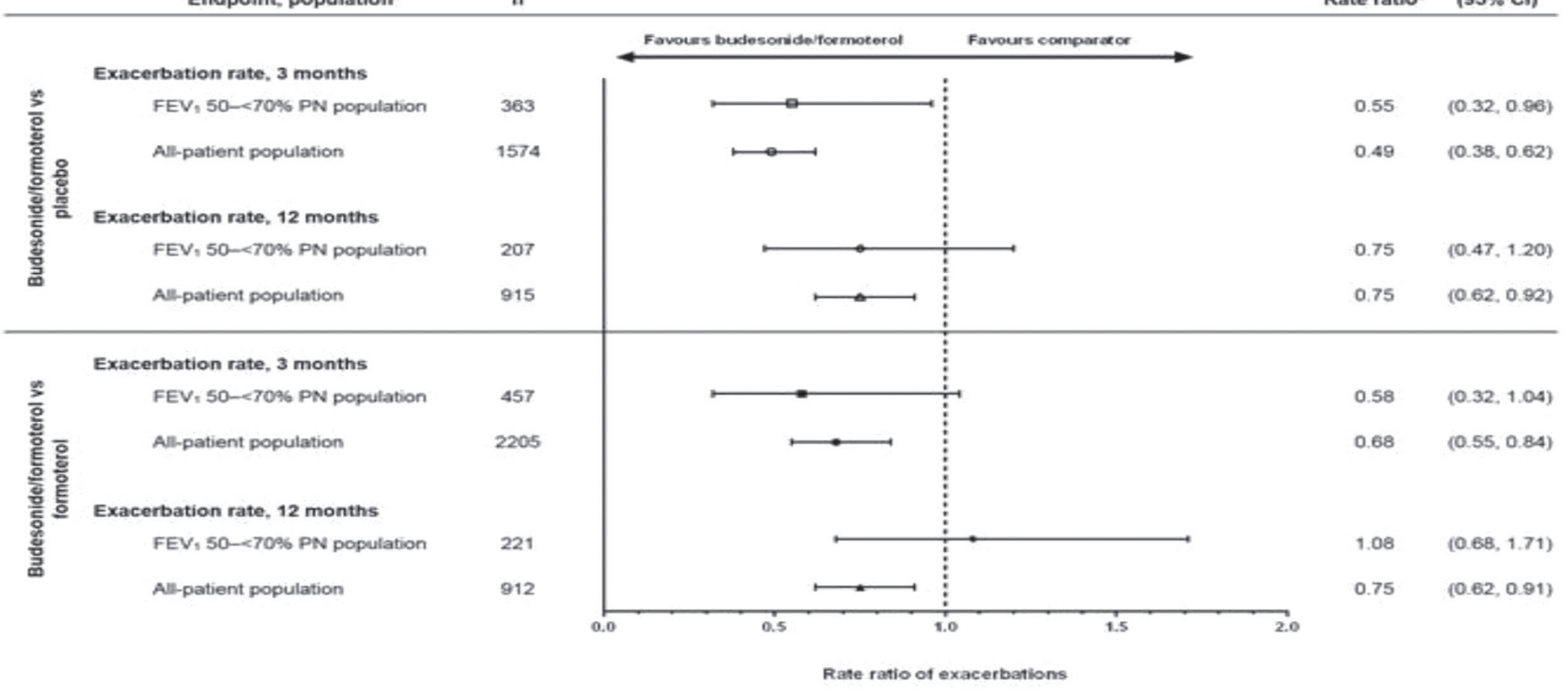

The rate ratio is the exacerbation rate ratio between budesonide/formoterol and the comparison treatment, determined by a negative binomial model

ANCONA, analysis of covariance: $\mathrm{Cl}$, confidence interval; $\mathrm{FEV}_{2}$, forced expiratory volume in one second LS, least squares; $n$, number of evaluable patients; PN, predicted normal

Abstract P58 Figure 1 Coparison of $\mathrm{FEV}_{1}(\mathrm{~A})$ and exacerbation rates (B) with budesonide/formoterol treatment vs placebo and vs formoterol for the $\mathrm{FEV}_{1} 50-<70 \%$ PN subpopulation and the all-patient population. Pooled data across four phase III/IV studies 
of budesonide/formoterol in the post-bronchodilator $\mathrm{FEV}_{1} 50$ $<70 \%$ of predicted normal (PN) subpopulation versus the allpatient population. This analysis supported the EU label change for Symbicort ${ }^{\circledast}$ Turbuhaler ${ }^{\circledast}$ to: 'symptomatic treatment of patients with COPD with $\mathrm{FEV}_{1}<70 \% \mathrm{PN}$ (post-bronchodilator) and an exacerbation history despite regular bronchodilator therapy'.

Methods Four randomised, double-blind, active- and/or placebocontrolled, studies in patients with moderate to very severe COPD were analysed. Key study inclusion criteria were pre-bronchodilator $\mathrm{FEV}_{1} \leq 50 \% \quad \mathrm{PN}$; use of short-acting bronchodilator; $\geq 1$ exacerbation in the past 12 months. Primary endpoints for the analysis were 3-month pre- and 3- and 12months post-bronchodilator $\mathrm{FEV}_{1}$ and exacerbation rates at 3and 12-months. Secondary endpoints included dyspnoea score, total symptom score, reliever medication use, night-time awakening and St George's Respiratory Questionnaire. Results for the post-bronchodilator $\mathrm{FEV}_{1} 50-<70 \% \mathrm{PN}$ subpopulation were compared with the all-patient population.

Results Of 3787 randomised patients, 832 (22.0\%) had postbronchodilator $\mathrm{FEV}_{1} 50-<70 \%$ PN. Baseline characteristics of the $\mathrm{FEV}_{1} 50-<70 \%$ subpopulation and the all-patient population were similar, except for baseline $\mathrm{FEV}_{1}$ parameters. The benefit of budesonide/formoterol versus placebo and formoterol on the primary and secondary endpoints were generally consistent between the $\mathrm{FEV}_{1} 50-<70 \%$ subpopulation and the all-patient population across all four studies and in the pooled analysis (Figure 1). No new safety signals were identified.

Conclusions In patients with COPD, the clinical efficacy and safety of budesonide/formoterol compared with placebo and formoterol was consistent between the post-bronchodilator $\mathrm{FEV}_{1} 50$ $-<70 \%$ PN subpopulation and the all-patient population, confirming the positive benefit/risk ratio in COPD patients with a post-bronchodilator $\mathrm{FEV}_{1} \quad<70 \% \quad \mathrm{PN}$ and a history of exacerbations.

\section{P59 FACTORS INFLUENCING STEP-UP TO LAMA+LABA/ICS IN COPD PATIENTS INITIALLY ON LAMA MONOTHERAPY: A THIN DATABASE STUDY}

${ }^{1} J R$ Hurst, ${ }^{2} \mathrm{M}$ Dilleen, ${ }^{2} \mathrm{~K}$ Morris, ${ }^{2} S$ Hills, ${ }^{2} \mathrm{~B}$ Emir, ${ }^{3} \mathrm{R}$ Jones. ${ }^{1}$ University College London, London, UK; ${ }^{2}$ Pfizer, New York, USA; ${ }^{3}$ Plymouth University Peninsula School of Medicine and Dentistry, Plymouth, UK

\subsection{6/thoraxjnl-2016-209333.202}

The potentially inappropriate use of inhaled long-acting beta agonist/corticosteroid (LABA/ICS) combinations in COPD patients for whom this treatment is not recommended has clinical and economic implications.

This retrospective analysis of anonymized electronic medical records in the UK Health Improvement Network (THIN) database was conducted to identify factors associated with step-up from long-acting muscarinic antagonist (LAMA) to LAMA $+\mathrm{LABA} / \mathrm{ICS}$ therapy. Secondary objectives included time to stepup, Global Initiative for Chronic Obstructive Lung Disease (GOLD) and Medical Research Council (MRC) classification. Data were included from COPD patients between 1 June 2010 and 4 September 2014, aged $\geq 35$ years at first LAMA treatment, with continuous enrolment $>360$ days before the index event (date of first LAMA prescription) who received LAMA monotherapy only prior to step-up. Time to step-up was analysed using a Cox regression model with time-varying covariates using a stepwise model selection procedure.

Data from 8773 patients (6199 LAMA [136 deaths]; 2438 LAMA+LABA/ICS) were included. Multivariable analysis revealed that exacerbations (composite), elective secondary care contact, markers of COPD proactive planned care, and reactive COPD care within the primary care setting were clinically and statistically significantly associated with step-up. Statistically significant factors negatively associated with step-up were being female and having diabetes (Table). Univariate analysis revealed FEV1, COPD severity and MRC classification to be significant predictors of step-up. These were not included in the multivariable model due to reduced observations, but sensitivity analyses including each in turn confirmed the above predictors. $28 \%$ of the cohort received step-up therapy, the majority (23\%) within 2 years of LAMA monotherapy initiation. Assessment per GOLD classification suggests that step-up was appropriate in most patients (group A, 18\%; B, 21\%; C, 26\%; D, 35\%). Assessment of MRC score (mean, median) in the step-up group (baseline: 2.45, 2.00; follow-up: $2.74,3.00$ ) suggests that patients who were stepped-up became more symptomatic prior to step-up.

These results show that COPD exacerbations were the most significant predictor of therapy step-up and that patients with initially stable disease are unlikely to require step-up. Therapy stepup appears to be appropriate in the majority of, but not all patients, and may reflect adherence to national guidelines.

\begin{tabular}{|c|c|c|c|}
\hline \multirow[t]{2}{*}{ Variable } & \multicolumn{3}{|c|}{$\begin{array}{l}\text { Multivariate Cox Regression } \\
\text { Analysis }\end{array}$} \\
\hline & HR & $95 \% \mathrm{Cl}$ & P-value \\
\hline Composite: exacerbations $^{\mathrm{a}}$ & 2.380 & $2.170,2.611$ & $<0.0001$ \\
\hline Elective secondary care contact & 1.445 & $1.305,1.601$ & $<0.0001$ \\
\hline $\begin{array}{l}\text { Markers of COPD proactive planned care within } \\
\text { primary care setting }\end{array}$ & 1.268 & $1.231,1.305$ & $<0.0001$ \\
\hline Reactive COPD care within primary care setting & 1.155 & $1.115,1.198$ & $<0.0001$ \\
\hline Composite: cardiovascular ${ }^{\mathrm{b}}$ & 1.150 & $1.025,1.291$ & 0.0175 \\
\hline Number of cough symptoms & 1.086 & $1.046,1.128$ & $<0.0001$ \\
\hline Number of short-acting bronchodilator prescriptions & 1.033 & $1.027,1.038$ & $<0.0001$ \\
\hline Age at index date ${ }^{c}$ & 0.992 & $0.988,0.995$ & $<0.0001$ \\
\hline Sex (female) & 0.798 & $0.735,0.867$ & $<0.0001$ \\
\hline Diabetes & 0.685 & $0.530,0.886$ & 0.0039 \\
\hline
\end{tabular}

\section{P60 EFFECT OF INDACATEROL/GLYCOPYRRONIUM (IND/GLY) ON PATIENT-REPORTED OUTCOMES IN MEN AND WOMEN WITH COPD: A POOLED ANALYSIS FROM THE IGNITE PROGRAMME}

${ }^{1} \mathrm{~K}$ Kostikas, ${ }^{2}$ Tsiligianni, ${ }^{3} \mathrm{~S}$ Fucile, ${ }^{1} \mathrm{~K}$ Mezzi, ${ }^{3} \mathrm{~S}$ Shen, ${ }^{3} \mathrm{D}$ Banerji, ${ }^{3} \mathrm{R}$ Fogel. ${ }^{1}$ Novartis Pharma AG, Basel, Switzerland; ' ${ }^{2}$ linic of Social and Family Medicine, University of Crete, Heraklion, Crete, Greece; ${ }^{3}$ Novartis Pharmaceuticals Corporation, East Hanover, NJ, USA

\subsection{6/thoraxjnl-2016-209333.203}

Introduction Literatures, although limited, suggest differences in the manifestations of COPD in terms of symptoms and healthrelated quality of life between men and women. Moreover, a 